\title{
Exploring the use of Plickers for conducting assessments in higher education
}

\section{Moretlo Tlale-Mkhize}

Department of Information Technology, Central University of Technology, South Africa.

\begin{abstract}
The emergence of new technologies has necessitated the need to explore new and innovative tools to conduct assessments in Higher education. One of these newest technologies is plickers which represent a student centered and student engagement during the delivery of course content. The focus of this paper is to explore the use of plickers for conducting assessments in higher education. Issues to be examined are, usability of plickers, tools that create studentcentred and student engagement environment. The issues to be explored include the following, first, the selection of appropriate technological assessment tool that does not hinder student learning. Second, the technology that provides immediate feedback to students and to guarantee effective teaching. Third, the cost effectiveness of the tool and its availability to facilitators. The paper is theoretical in nature and use and is mainly interpretive (qualitative inquiry). It is argued that plickers is one of the innovative and yet unexplored tools that can be embraced to conduct assessments in the current technological changes. Furthermore, the paper argues that plickers enhances student engagement during class and provide immediate feedback to the formative assessment.
\end{abstract}

Keywords: Plickers; formative assessment; assessment tool; student engagement. 


\section{Introduction}

The use of Information Communication Technologies (ICT) has been thriving worldwide in the last few decades. Its use has also impacted the instructional delivery in higher education (HE), and has shown potential to support learning and teaching in a number of ways (Wrenn \& Wrenn, 2009). Therefore, there is a need for a technology that can be intergrated seamlessly into teaching and learning. In today's teaching and learning, lecturers are keen in measuring the outcomes of their lessons (Chng \& Gurvitch, 2018). The traditional way of assessing students is burdensome. As a result, Higher Education Institutions are seeking approaches and alternatives to assess students and seek ways to give them timely feedback. The technology that can support lecturers with the challenges of collecting real-time formative assessment data quickly from students is the use of plickers. Plickers is a software that is conveniently and freely available for use. There is no need for the students to use any hardware device when participating in formative assessments during class. Currently, there are two choices to conduct formative assessments during class by using Learning Management system (LMS) or Clickers at one University of Technology. LMS requires each student to use a computer. Additionally, clickers require each student to have clicker device that they will use to answer the questions.

\section{What is plickers}

Plickers are a student response that uses online software system which can be characterized as a low-technology tool (Chng \& Gurvitch, 2018; McClure \& McAndrews, 2016). It is a tool for collecting real time assessment data that saves time for marking. According to Kent (2019a), it can also stimulate active learning and focus the attention of the student. Additionally, it promotes active learning as it allows students to participate during class. Subsequently, it promotes learning and does not obstruct learning. It simply requires the facilitator to login into plickers website (www.plickers.com), use the camera enabled smartphone to access the plickers application, and each student to have the printed plickers card. It facilitates the asking of questions and provides feedback during the lecture (McClure \& McAndrews, 2016; Wood, Brown, \& Grayson, 2017). It can also be utilized for monitoring daily progress and attendance (Krause, O'Neil, \& Dauenhauer, 2017). The results are stored in the database for a lecturer to view them later if they need to (Lowe, Macy, \& Stone, 2019).

\section{Literature review}

Lecturers have the responsibility of selecting tools that create a student-centred and student engaging learning situation while delivering course content. It is important to select the accurate and most appropriate technology to guarantee effective teaching, while avoiding technologies that seems to obstruct learning (Freeman \& Tashner, 2015). As technology 
changes, so are the learning needs of the students (McClure \& McAndrews, 2016) that needs to be met. One of the students' needs is receiving immediate feedback to know how they performed in an assessment. The need for immediate feedback requires the intergration of technology into teaching and learning.

Research indicates that student learning development can be supported by enhancing assessment and feedback which might be in a form of formative or summative assessment (Dixson \& Worrell, 2016). One of the importance of assessing students learning is to award the university degrees (Deeley, 2018). Furthermore, it specified that students who participated in quizzes performed better in their examination compared to their counterparts who never participated (Price \& Kirkwood, 2011). Therefore, plickers offers a fun and useful way to involve students in the learning process (Frey, 2020).

\section{Current situation}

Currently, there are two choices to conduct formative assessments during class by using LMS or Clickers at one University of Technology. LMS requires each student to use a computer and not all lecture rooms are equipped with computers for each student to use during class time. Problem with LMS is that it requires the student to login with their password. Password expires every 30 days for security purposes, as a result, it requires to be reset with a new password before it expires. Most students don't bother resetting the password until it is required, which might take time to go and reset it with the administrator when it has expired.

To solve the problem of using LMS, clickers was introduced. Clickers are an interactive PowerPoint presentation that allows users to interact actively in class. However, clickers need each student to have the device they will use to respond to questions and a receiver attached to the computer that the lecturer will use to obtain the answers. Answers are sent to the receiver, and the system collects the results and aggregates results in a graph form for the students to see (Berry, 2009).

The probable challenge with clickers is that you need to wait for all the students to respond, which might be a challenge to know who has not responded. The students also need to be familiar with the device to be able to answer the questions. Moreover, if the other lecturer has requested the devices from the administrator, the other lecturers must wait for the devices to be available. As a result, lecturers become discouraged to use the devices and opt for traditional methods of assessing student, which consumes time.

Plickers is a new audience response system (Wood et al., 2017) that is seen as a solution to address these problems which is simple and inexpensive to implement. It does not require students' prior knowledge to use the software. All they need to do is to hold the plickers card 
so that it can be scanned. Furthermore, lecturers can save time of attending the training to use the clickers software and LMS in order to conduct assessments.

\section{The role of formative assessment in class}

Students are different in terms of their learning need in class. What the lecturer does in classroom plays a significant role in student learning process. According to Wiliam and Leahy (2016) education is concerned with increasing the student engagement and to make classroom process more responsive to students' needs. One way to do engage students in class is to involve them in lesson by asking them questions during the lesson. Feedback can be discussed immediately to clarify misunderstandings in the lesson. When formative assessment is used effectively, students develop the ability to identify gaps in their learning and develop skills and content needed to improve on their learning (Wiliam \& Leahy, 2016). Students are able to gain insights into their level of understanding and competence. This also assist students to play an an active role in their learning instead of only acquiring the information during classes. The active role provides the students with the opportunity to speak up, listen to other students, and reflect back on their learning (Mshayisa, 2020). In other words, students can put to practice what they have learned and measure their success. The students can also examine if they have achieved lessons' outcomes. The use of formative assessment to monitor students progress assist in identifying students that are at risk earlier so that their needs can be attended to. Tools such as plickers are beneficial for formative assessment to improve student learning and to assist in indicating where improvement is needed.

\section{Benefits of plickers}

Despite the fact that everything is done online, which requires that there should be internet connection throughout the session; the benefits outweighs the challenges. The first benefit is that it is a free online tool for gathering real-time assessment data. As a result, the lecturer can ask questions and receive immediate feedback from students in class (Wood et al., 2017), which increases student engagement and participation in class. Active engagement of students in class is recognized by Kent (2019b) to lead to a better recall and utilization of information. Student performance in assessments improve when students are able to recall what they have learned.

To collect the answers to the questions, the teacher raises the smartphone and students tend the cards with their respective answers and smartphone picks up information in a database. This benefit makes it an inexpensive tool because students need not to have or use any technological equipment during the assessment. Most lecture rooms are equipped with the 
projector that is used to present the lessons, which makes it possible for the facilitator to project the questions for the students. It is simple, usable and time saving.

Furthermore, the Plickers program generates the response straightaway (Chng \& Gurvitch, 2018; McClure \& McAndrews, 2016). In the light of this, the lecturer can determine if the lesson was understood by the students (Chng \& Gurvitch, 2018). When a gap is discovered in the learning needs of the students, the lecturer can develop the question for students to answer. The lecturer can determine if the lesson goals were achieved or not immediately. It supports constructive feedback in that the results are relevant for that particular lesson and are immediate (Ovando, 1992). Moreover, there is no need to wait for the lecturer to mark the assessment and keep the students in suspense on how they did in their assessments.

Plickers offers an option to archive the reports or discard them; print reports for the individual students and to export the reports in a CSV format. Another benefit of plickers is that there's no need to wait for the students to login. They can participate in assessment as long as they have the QR code cards. All that is needed is to implement the use of plickers is mainly dependant on the facilitator and not on the participants.

\section{Implementation of plickers}

To use plickers in a lecture room, firstly, both a computer that will be used to display questions on a projector for the respondents and a mobile device should have internet connection. Secondly, plickers card for each respondent are required to be able to conduct formative assessment. The respondents do not need to have any device with them to participate in the assessment. The process to use plickers includes the creation of the account, adding the class and the respondents to the class. Respondents can be added anonymously depending on the objective of the assessment. The assessment is a combination of true or false and multiple choice questions. The participants uses the assigned plickers card as per their registration to answer the questions that are projected from the computer, and the facilitator captures their answers by using the plickers application. Each card has the respondent details embedded within and has four possible answers, i.e., A, B, C, and D displayed on four sides accordingly to form the unique QR code. The cards are displayed in a PDF format which is also available to download for free or can be printed directly from the website. It is recommended that the cards be printed on a white paper or cardstock so that the plickers application reads them speedily and effortlessly. Furthermore, the cards can be made durable by pasting them on the hard cover of notebook or card box, especially if they are going to be handled by many respondents. Alternatively, cards can be purchased from online commercial stores that offers quality material. However, laminating the cards yourself is not recommended because it might hinder the process of scanning the results. The laminated cards has a glossy look that makes it difficult for the camera to read the respondent's answer, 
especially when there lights are on in the room. Another disadvantage is that they require special care so that they don't have fingerprints that can hide the answer.

To answer the question, the respondents hold up their cards to show the preferred answer for the facilitator to scan the answer by holding up their cards with the preferred answer facing up. To ensure reliability of the assessment, the letters on the cards for the answer are too small for the respondents to copy each other or disclose to each other their answer. The cards should be visible to the mobile device of the facilitator to pick up the information.

The respondents reveal the cards with their respective answers and the facilitator raises the camera enabled mobile device to record the respondents' answers. The mobile device with the application picks up information in a database. The device shows the respondent information when scanning the responses to indicate the responses were received. It picks up the information about the respondent assigned to the card and captures the response. Connection should be established if the device does not pick up the details of the respondents. The responses of the respondents will be matched with the one in the database, and correct and incorrect responses will be recorded.

The reports section displays the results instantly for all the respondents to see who has answered the question correctly. The results are displayed as spreadsheet, each corresponding to the respondents' results. Furthermore, they can reveal the respondents' understanding of the lesson. The lecturer can choose to print reports for individuals, archive or clear the reports. Furthermore, the results can be filtered by class if there is more than one class. The reports can later be used for summative assessment to formally record them and for the respondents to view them.

\section{Discussions and conclusion}

Plickers is an emerging approach for assisting in delivery of content and for conducting assessments which has the potential to assist lecturers with the challenges of collecting realtime formative assessment data quickly from students. The assessments are done in real time and the results are available immediately. Students are eager in knowing how they performed in assessments in time. Timely feedback helps students and lecturers to take action earlier if needed.

Plickers create an enabling environment for the student to participate in class. This type of participation creates an engagement about the lesson at hand without the need of hardware for the students. This enables all students to participate during class activities and assessments. It also enables the students who are shy to participate in class to do so without feeling ashamed. 
Paper based cards can be used to print the cards that will be used to scan the responses. Additionally, lecturer can determine students' knowledge and understanding about the lesson while still on the same subject. Questions can be prepared and loaded beforehand or can be done on the fly as the need arises. The application does support lecturers who realize that there is a question that needs to be asked at a particular time during class.

This paper demonstrates how facilitators can take an advantage of this inexpensive tool for conducting formative assessments. Plickers is a suggested tool that can be incorporated seamlessly during class time. There is no need for students to learn how to operate new technology to successfully use it.

The paper argued that plickers is one of the innovative and yet unexplored tools that can be embraced to conduct assessments in the current technological changes. Moreover, the paper argued that plickers enhances student engagement during class and provide immediate feedback to the formative assessment. The main aim of the paper was to highlight and suggest the use of plickers as an assessment tool when conducting formative assessments in higher education.

\section{References}

Berry, J. (2009). Technology support in nursing education: Clickers in the classroom. Nursing education perspectives, 30(5), 295-298.

Chng, L., \& Gurvitch, R. (2018). Using Plickers as an Assessment Tool in Health and Physical Education Settings. Journal of Physical Education, Recreation \& Dance, 89, 19 25. doi:10.1080/07303084.2017.1404510

Deeley, S. J. (2018). Using technology to facilitate effective assessment for learning and feedback in higher education. Assessment \& Evaluation in Higher Education, 43(3), 439448.

Dixson, D. D., \& Worrell, F. C. (2016). Formative and summative assessment in the classroom. Theory into practice, 55(2), 153-159.

Freeman, C. L., \& Tashner, J. (2015). Technologies for Formative Assessment: Can WebBased Applications Transforms the Allied Health Science Classroom and Improve Summative Assessment Outcomes. Appalachian State University, USA.

Frey, C. M. (2020). Using Plickers and an iPad Pro to Enhance Learning in Elementary Statistics.

Kent, D. (2019a). Plickers and the Pedagogical Practicality of Fast Formative Assessment. Teaching English with Technology, 19(3), 90-104.

Kent, D. (2019b). Viability of Employing the Plickers SRS in the Korean TEFL University Setting. Journal of Asia TEFL, 16(1), 385.

Krause, J. M., O'Neil, K., \& Dauenhauer, B. (2017). Plickers: A formative assessment tool for K-12 and PETE professionals. Strategies, 30(3), 30-36. 
Lowe, M. S., Macy, K. V., \& Stone, S. M. (2019). Contingent teaching through low-tech audience response systems: Using Plickers to support student learning and assessment.

McClure, C., \& McAndrews, L. (2016). Going native to reach the digital natives: new technologies for the classroom. 2016 ITAA Annual Conference Proceedings, 12, 8-10.

Mshayisa, V. V. (2020). Students' perceptions of Plickers and crossword puzzles in undergraduate studies. Journal of Food Science Education.

Ovando, M. N. (1992). Construction feedback: a key to successful teaching and learning. 12. doi:ED419696

Price, L., \& Kirkwood, A. (2011). Enhancing professional learning and teaching through technology : a synthesis of evidence-based practice among teachers in higher education Other. Higher Education Academy, York, UK.

Thomas, J., Lopez-Fernanda, V., LIamas-Salguero, F., Martín-Lobo, P., \& Pradas, S. (2016). Participation and knowledge through Plickers in high school students and its relationship to creativity. Paper presented at the UNESCOUNIR ICT \& Education Latam Congress.

Villarroel, R., Cornide-Reyes, H., Muñoz, R., \& Barcelos, T. (2017). Flipped classroom+ plickers, an experience to propitiate collaborative learning in software engineering. Paper presented at the 2017 36th International Conference of the Chilean Computer Science Society (SCCC).

Wiliam, D., \& Leahy, S. (2016). Embedding formative assessment: Hawker Brownlow Education.

Wood, T. A., Brown, K., \& Grayson, J. M. (2017). Faculty and student perceptions of plickers. ASEE Zone II Conference.

Wrenn, J., \& Wrenn, B. (2009). Enhancing learning by integrating theory and practice. International Journal of Teaching and learning in higher education, 21(2), 258-265. 